\title{
Políticas públicas para Educação Infantil e direito à educação: avanços e lacunas em âmbito municipal
}

\author{
Public Policies for Early Childhood Education and the right to education: advances \\ and gaps at the municipal level
}

\section{Politiques publiques pour l'education des enfants et le droit a l'education: avancees et lacunes dans un cadre municipal}

Leonice Matilde Richter ${ }^{1}$ Universidade Federal de Uberlândia

Maria Vieira Silva ${ }^{2}$

Universidade Federal de Uberlândia

Resumo: Analisa avanços e lacunas na implementação de políticas públicas voltadas para a Educação Infantil, consubstanciadas em dispositivos legais em âmbito nacional e na materialização da meta 1 do Plano Decenal Municipal de Educação de Ituiutaba (PDME), Minas Gerais (Lei n. 4.368/2015). A referida meta dispõe sobre a universalização da Educação Infantil na pré-escola e a ampliação da oferta em creches, de forma a atender, no mínimo, $50 \%$ das crianças de até três anos até o final da sua vigência. Constituem-se ainda como objetos de análise os dados quantitativos das instituições de Educação Infantil do município supracitado, a base de dados da Pesquisa Nacional por Amostra de Domicílios (PNAD), o censo demográfico e os censos da Educação Básica. O trabalho evidencia a necessidade de a sociedade civil avaliar o desenvolvimento dos Planos, uma vez que as indicações oficiais quanto à concretização das metas apresentam discrepâncias que mascaram estratégias para anunciar o cumprimento da meta.

Palavras-chave: Políticas Públicas de Educação. Plano Decenal Municipal de Educação. Educação Infantil.

Abstract: This paper analyzes the advances and gaps in the implementation of public policies for Early Childhood Education, based on legal provisions at the national level and on the materialization of goal 1 of the Municipal Decennial Education Plan of Ituiutaba, Minas Gerais, Brazil (Law 4368/2015). This goal provides for the universalization of Early Childhood Education in pre-school for children from four to five years old and the expansion of offering Early Childhood Education in nursery schools, in order to attend at least $50 \%$ of children up to three years old until the end of the term, in 2025. The quantitative data of the institutions of Early Childhood Education of the municipality mentioned above, the National Household Sample Survey database, the demographic census and the basic education censuses constitute the analyses objects. The work shows the need for civil society to evaluate such documents, since the official indications regarding the implementation of goals

\footnotetext{
${ }^{1}$ Doutora em Educação pela UFU. Professora da Universidade Federal de Uberlândia, atuando no Instituto de Ciências Humanas do Pontal.E-mail: leonice@ufu.br

2 Doutora em Educação pela UNICAMP. Professora da Universidade Federal de Uberlândia, atuando no Programa de Pós-graduação em Educação (Mestrado e Doutorado) no âmbito da Linha de Pesquisa Estado, Políticas e Gestão em Educação.E-mail:mvs@ufu.br
} 
present discrepancies and actions that conceal strategies to announce the compliance of the target.

Keywords: Public Education Policies. Municipal Decennial Education Plan. Early Childhood Education.

Résumé: Cet article analyse les avancées et les lacunes de la mise en œuvre de politiques publiques concernant l'éducation des enfants inscrites dans des dispositifs légaux au niveau national et dans l'objectif numéro un du Plan décennal municipal d'Éducation (PDME) de la ville d'Ituiutaba, dans l'état de Minas Gerais (Loi n 4.368/2015). Ce dernier prévoit l'universalisation de l'éducation des enfants à la maternelle pour les enfants de quatre à cinq ans et l'élargissement de l'offre d'éducation des enfants dans les crèches, de manière à recevoir pour le moins 50\% de ceux de moins de trois ans, avant son expiration en 2025. D'autres objets d'analyse sont les données quantitatives des établissements d'éducation pour enfants de la ville en question, la base de données de la Pesquisa Nacional por Amostra de Domicílios (PNAD - Recherche nationale par échantillon de domiciles) et les recensements de la population et de l'éducation de base. Ce travail montre clairement que la société civile doit évaluer le développement des Plans, car les indications officielles sur la réalisation des objectifs révèlent des divergences et certaines actions masquent des stratégies pour annoncer l'atteinte du but.

Mots-clés: Politiques publiques d'éducation. Plan décennal municipal d'éducation. Éducation des enfants.

\section{Introdução}

As políticas públicas de oferta da educação formal para crianças pequenas são relativamente recentes na realidade brasileira e, em grande medida, resultam da mobilização da sociedade civil em prol da garantia da universalização do acesso e da qualidade de creches e pré-escolas. Isso demanda do Estado medidas que garantam os direitos fundamentais das crianças, especialmente daquelas oriundas dos estratos empobrecidos da população.

Esse movimento foi impulsionado e relacionado a um contexto mais amplo de ações e manifestações sociais em prol da abertura política na década de 1980 (FARIA, 1999). Nesse entremeio, a Educação Infantil obteve importante repercussão na Constituição Federal (CF) de 1988, a qual a reconhece como direito subjetivo da criança ao dispor, no Art. 208, o dever do Estado em garanti-la em creches e pré-escolas para crianças de até cinco anos de idade (Redação da Emenda Constitucional (EC) n. 53/2006); e como direito de trabalhadores urbanos e rurais (Art. $7^{\circ}$; Redação da EC n. 53/2006). De tal modo, a Educação Infantil como 
responsabilidade do Estado deve ser ofertada de forma gratuita, não obrigatória e independentemente de classe social, gênero, raça e etnia.

Diante disso, o resultado do processo histórico que envolveu os movimentos comunitários, de mulheres, trabalhadores, pesquisadores, entidades e profissionais da educação em defesa da educação. O cuidado da criança pequena requer esforço para consolidar tais conquistas legais, além de garantir que as políticas públicas a respeitem como cidadã criativa e social, que se constitui (e é constituída) na história e na cultura contemporâneas a ela, o que demanda a qualidade específica ao atendimento das condições para a efetivação da Educação Infantil.

Nos anos seguintes à promulgação da CF (BRASIL, 1988), esse direito é reafirmado no Estatuto da Criança e do Adolescente (ECA, 1990) e delineado na Lei de Diretrizes e Bases da Educação Nacional (LDB, Lei n. 9.394/96), na qual a Educação Infantil passa a integrar a Educação Básica como a primeira etapa, seguida pelos Ensinos Fundamental e Médio. Ainda na década de 1990, houve outras publicações para essa etapa da educação, como o Referencial Curricular Nacional para a Educação Infantil (RCNEI, 1998) e as Diretrizes Curriculares Nacionais para a Educação Infantil (DCN, BRASIL, 2010, p.11), que estabelece as Diretrizes “a serem observadas na organização de propostas pedagógicas na Educação Infantil”.

Quanto ao acesso à Educação Infantil, com a EC n. 59, de 11 de novembro de 2009, que alterou o Art. 208 da LDB (BRASIL, 1996a), a Educação Básica passa a ser "obrigatória e gratuita dos 4 (quatro) aos 17 (dezessete) anos de idade", incluindo a faixa etária de quatro e cinco anos, referente a crianças com direito à pré-escola. Nesses termos, o atual Plano Nacional de Educação (PNE) (BRASIL, Lei n. 13.005/2014) definiu como primeira meta a universalização, até 2016, da Educação Infantil na pré-escola e a ampliação da oferta em creches, de forma a atender, no mínimo, $50 \%$ das crianças de até três anos e o final da vigência do Plano. Conforme a EC n. 59 (2009), a universalização da educação para crianças de quatro e cinco anos é reforçada nos Planos, além da responsabilidade com a ampliação das creches.

O PNE (BRASIL, 2014) determina a elaboração de planos estaduais e municipais que deveriam ser organizados em consonância com tal documento. O Plano Decenal Municipal de Educação (PDME) é expresso no Art. 214 da CF (BRASIL, 1988), no Art. 11, Inciso I da LDB (BRASIL, 1996a) e na Lei n. 19.481/2011, que institui o Plano Decenal de Educação no Estado de Minas Gerais (PDEMG). 
No presente artigo é analisada a realidade da Educação Infantil no município de Ituiutaba, Minas Gerais, quanto à consecução da meta 1 do PDME (ITUIUTABA, Lei n. 4.368/2015). A referida meta está de acordo com a meta 1 do PNE (BRASIL, 2014), ao preconizar a universalização, até 2016, da Educação Infantil na pré-escola para as crianças de quatro a cinco anos de idade, além da ampliação da oferta de Educação Infantil em creches, de forma a atender, no mínimo, $50 \%$ das crianças de até três anos até o final da vigência do PDME.

Para tanto, serão desenvolvidas análises dos documentos emanados da esfera governamental, no âmbito da Secretaria Municipal de Educação. Como referência de estudos, utilizar-se-ão dados quantitativos das instituições de Educação Infantil do município de Ituiutaba/MG, da base de dados da Pesquisa Nacional por Amostra de Domicílios (PNAD), do censo demográfico e dos censos da Educação Básica, com as informações do município acerca do número de crianças atendidas.

\section{Educação Infantil: oferta em regime de colaboração}

Diferentemente dos países europeus e, inclusive, os da América Latina (Chile, Argentina e Uruguai), os quais implementaram os sistemas nacionais de ensino na segunda metade do século XIX, com a emergência dos Estados nacionais (SAVIANI, 2008), no Brasil ocorreu um déficit histórico devido à tentativa tardia de garantir o Sistema Nacional de Educação. Para Saviani (2008), a utilização difusa do conceito no país está associada à "noção de que o termo 'sistema' denota conjunto de elementos”; por isso, há a assimilação “a conjunto de unidades escolares ou de rede de instituições de ensino". Contudo, o sistema "denota um conjunto de atividades que se cumprem tendo em vista determinada finalidade. [...] implica organização sob normas próprias (o que lhe confere um elevado grau de autonomia) e comuns (isto é, que obrigam a todos os seus integrantes)" (SAVIANI, 2008, p. 215).

No Brasil, ainda de acordo com o autor supramencionado, há quatro tipos de obstáculos na constituição do sistema: econômicos, marcados pela resistência à manutenção do ensino público; políticos, devido à descontinuidade das iniciativas de reforma da educação; filosófico-ideológicos, concebidos por ideias e interesses opostos ao sistema nacional de educação; e legais, contrários à aprovação de uma legislação que permite a organização do ensino como um sistema nacional. 
A organização político-administrativa da República Federativa do Brasil, expressa no Art. 18 da CF (1988), abarca a União, os estados, o Distrito Federal e os municípios como entes definidos como autônomos. No Capítulo VI - Da Intervenção, Art. 34, VII, C, reafirma-se a "autonomia municipal”, desde que não fira os princípios constitucionais, e assim reconhece os municípios como entidades infraestaduais e autônomas.

No âmbito da educação, segundo a CF (1988), compete privativamente à União legislar sobre as “diretrizes e bases da educação nacional” (XXIV), mas define, no parágrafo único, que "Lei complementar poderá autorizar os Estados a legislar sobre questões específicas das matérias relacionadas neste artigo”. Quanto ao Capítulo III - Da Educação, da Cultura e do Desporto, a relação de colaboração entre os entes federados é reafirmada no Art. 24, que sustenta que "Compete à União, ao Estado e ao Distrito Federal legislar concorrentemente sobre: [...] IX - educação, cultura, ensino e desporto”, bem como no Art. 211.

Em relação aos municípios, Saviani (2008, p.218) assevera que, se na CF (1988) a função de legislar permanece dúbia, “[...] já não pairam dúvidas, à luz do texto da LDB (BRASIL, 1996a), quanto à competência dos municípios para instituir os respectivos sistemas de ensino". No que tange à política de financiamento da educação pública no Brasil, se estabelece o regime de colaboração entre a União, os estados, o Distrito Federal e os municípios.

Nesse aspecto, a garantia do acesso à educação é assumida como responsabilidade comum entre União, estados, o Distrito Federal e os municípios que devem proporcionar meios de acesso à cultura, à educação e à ciência (BRASIL, 1988). Constitucionalmente é compartilhado com a União, ainda que em níveis de abrangência diferentes (privativo, complementar, concorrentemente ou de competência comum), o gozo de gerir os sistemas de ensino, tanto pelos estados quanto pelos municípios.

A União delega aos estados poder para legislar sobre a educação, especialmente no artigo 24, e, no artigo 25, compartilhar competências materiais que dizem respeito à organização da estrutura e do funcionamento do ensino, proporcionando os meios de acesso à educação, cultura e desporto. Então, enquanto Federação, a União compartilha com estados e municípios não só o poder de legislar, como também o de estruturar o sistema de ensino (COSTA, 2010, p.112).

Com a EC n. 14/1996b e, posteriormente, a EC n. 53/2006, há definições um pouco mais claras quanto à forma de colaboração, embora se limite a delegar, também a leis 
complementares, a acepção específica das normas. Aos municípios, como destaca o Art. 30, VI, compete “[...] manter, com a cooperação técnica e financeira da União e do Estado, programa de educação pré-escolar e de Ensino Fundamental”. O estado não intervirá em seus municípios, tampouco a União nas cidades localizadas em território federal, exceto quando: [.... III - não tiver sido aplicado o mínimo exigido da receita municipal na manutenção e desenvolvimento do ensino […] (BRASIL, 1988; EC n. 64/2010).

A aproximação dessa relação entre os entes e a União assume nuanças particulares na gestão do então Presidente da República, Luiz Inácio Lula da Silva (2003-2010), e na orientação do então ministro da Educação, Fernando Haddad, com a publicação do Plano de Desenvolvimento da Educação (PDE) em 2007. A normatização inicial, conforme o Decreto n. 6.094, de 24 de abril de 2007 (BRASIL, 2007a), implementa o Plano de Metas Compromisso Todos pela Educação pela União, em regime de colaboração com municípios, Distrito Federal e estados, além da participação das famílias e da comunidade, mediante programas e ações de assistência técnica e financeira, visando à mobilização social pela melhoria da qualidade da Educação Básica, como define o Art. $1^{\circ}$ do Decreto n. 6.094 (BRASIL, 2007a).

Esse apoio da União se define mediante a elaboração de um Plano de Ações Articuladas (PAR), conjunto apoiado técnica ou financeiramente pelo Ministério da Educação (MEC), que visa ao cumprimento das metas do Compromisso e à observância das suas diretrizes (Decreto n. 6.094, Art. $9^{\circ}$ ), sendo, naquele momento, a base para a cooperação entre o MEC e o ente apoiado. Após o diagnóstico da educação local, o ente elabora o Plano com o auxílio da equipe técnica - seja qual for o resultado, o apoio se limita à gestão educacional, à formação de professores e profissionais de serviços e apoio escolar, aos recursos pedagógicos e à infraestrutura física.

Pode-se considerar que a infraestrutura de sustentação do PDE se assenta nos pilares técnico e financeiro, em correspondência com a dupla assistência que, conforme a CF e a LDB, é atribuição do MEC. Do ponto de vista técnico, o PDE se apoia em dados estatísticos atinentes ao funcionamento das redes escolares de Educação Básica e em instrumentos de avaliação construídos segundo indicadores do aproveitamento. Assim, para acompanhar o compromisso firmado entre os entes federados, se instituiu o Sistema Integrado de Planejamento, Orçamento e Finanças do Ministério da Educação (SIMEC), além de resoluções lançadas pelo Fundo Nacional de Desenvolvimento da Educação (FNDE). Tais dispositivos legislativos estabelecem critérios, parâmetros e procedimentos para a 
operacionalização da assistência financeira suplementar e voluntária a projetos educacionais, no âmbito do Compromisso Todos pela Educação.

Adrião e Garcia (2008, p.780) ponderam que nessa política há uma opção por “[ [...] responsabilizar as gestões municipais pelo padrão da oferta educativa nos municípios”. Segundo as autoras, desde o redesenho da oferta da educação pública, o Fundo de Manutenção e Desenvolvimento do Ensino Fundamental e Valorização do Magistério (FUNDEF) (BRSIL, Lei n. 9.424/1996c) levou os municípios a assumirem papel de destaque na oferta educacional, posto que enfrentam obstáculos de uma estrutura pouco aparelhada e com limites de recursos; assim, “[ [...] não é de se estranhar que, em um novo esforço de regulação, o MEC tenha proposto, em 2007, a instituição de uma programa de apoio técnico e financeiro" (Ibidem, p.786) voltado para os municípios com mais dificuldades, desde que se submetam a certos mecanismos de accountability, como tornar públicas as informações, participar das avaliações em larga escala federal e receber recursos e assistência técnica, com a consequente execução do PAR desenvolvido sob responsabilidade das gestões locais, com vistas a elevar as metas estabelecidas pela União. Vale dizer que o desequilíbrio econômicofinanceiro diretamente relacionado à distribuição histórica da riqueza no país entre os entes federados traz implicações à educação e à autonomia dos municípios; logo, há de se considerar o olhar das políticas públicas para tais questões, sem desvelar da rigorosidade crítica.

De fato, a elevação dos recursos é fundamental na ampliação do acesso e da qualidade da educação, mas esse é um dos pontos mais conflituosos na relação da União com os entes federados, a exemplo dos embates acerca do PNE 2001-2010, documento aprovado sem a indicação do recurso financeiro - dentre as metas vetadas pelo então Presidente Fernando Henrique Cardoso estava a que definia o Produto Interno Bruto (PIB) destinado à educação. Com isso, obteve-se um plano que não tinha base financeira para ser realizado (DOURADO, 2011).

Com a aprovação do PNE (Lei n. 13.005) em 25 de julho de 2014, com vigência de 2014 a 2024, a meta 20 traz uma contribuição ao enfrentamento na atuação efetiva da União, ao definir a ampliação do investimento “[ [...] público em educação pública de forma a atingir, no mínimo, o patamar de $7 \%$ (sete por cento) do Produto Interno Bruto (PIB) do País no $5^{\circ}$ (quinto) ano de vigência desta Lei e, no mínimo, o equivalente a 10\% (dez por cento) do PIB ao final do decênio”. Essa realidade se origina da luta histórica de movimentos e associações imbuídos na defesa da educação. 
No contexto atual, constata-se o recuo na ação da União. Em uma conjuntura política marcada por retrocessos políticos e sociais, o governo de Michel Temer (Movimento Democrático Brasileiro), especialmente por meio da EC n. 95, de 2016, institui o Novo Regime Fiscal, colocando um teto dos gastos com despesas primárias por 20 anos. Os impactos dessa lei, de certo modo, lançam sobre o atual PNE um prenúncio de que haverá novamente um plano sem base financeira para ser efetivado.

Ao avaliar a Lei n. 13.587, de 2 de janeiro de 2018 (BRASIL, 2018a), que estima a receita e fixa a despesa da União para o exercício financeiro de 2018, observam-se impactos na EC 95/2016 para a educação. Nesse caso, Michel Temer faz um único veto, que versa sobre a elevação de $\mathrm{R} \$ 1,5$ bilhão para o FUNDEB, como mostra a Mensagem n. 1, de 2 de janeiro de 2018 :

Razões do veto "A programação destinada à Complementação ao Fundeb teve sua dotação elevada em $\mathrm{R} \$$ 1.500.000.000,00 em relação ao PLOA2018 enviado pelo Poder Executivo. Não obstante essa despesa não se sujeitar ao teto de gastos instituído pela EC no 95/2016, destaca-se a grave situação fiscal que se aventa para 2018 e o impacto que essa medida terá sobre as contas públicas. Diversas medidas de contenção de despesas estão sendo instituídas, de forma que diversos órgãos da Administração Pública Federal estão sendo contemplados com recursos mínimos para seu funcionamento e manutenção. Nesse contexto, tal mudança no Fundeb poderá comprometer o equilíbrio das contas públicas, essencial para a recuperação econômica do País. Assim, permanece reservado ao Fundo o montante de $\mathrm{R} \$$ 14.054.309.473,00 (BRASIL, 2018a).

Nessa conjuntura, notam-se incongruências para a efetivação do PNE (BRASIL, 2014) e a relevância da sociedade civil no monitoramento das metas, sobretudo diante do desmonte do Fórum Nacional de Educação (FNE), ao ser restringido quanto à responsabilidade de conduzir e coordenar as Conferências Nacionais de Educação (CONAES), espaço passível de acompanhar, monitorar e problematizar a efetivação do Plano, como consta no próprio PNE (BRASIL, 2014). O Fórum é uma demanda antiga da sociedade civil que foi conquistada nas deliberações da CONAE de 2010 e efetivada por meio da Portaria n. 1.407, de dezembro de 2010, mas posteriormente revogada pela Portaria n. 577 (BRASIL, 2017a). Como destacam os editores da Revista Educação \& Sociedade (2017, p. 1) em Carta Aberta ao Ministério da Educação:

Portaria do MEC n. ${ }^{\circ} 577$ desmonta a estrutura atual do FNE (Fórum Nacional de Educação) e, para a nova composição, não menciona expressamente as finalidades e competências do Fórum. Amplia a representação governamental e empresarial, reduz a participação da representação da Sociedade [...]. 
Parece difícil acompanhar efetivamente a concretização do PNE (BRASIL, 2014). Ações de resistência foram construídas, como pode ser acompanhado no editorial da revista Educação \& Sociedade (2017), em que se manifesta em apoio à organização da sociedade civil e de entidades para a promoção da Conferência Nacional Popular de Educação (CONAPE) a ser realizada, sem a participação do MEC, por movimentos sociais e entidades da educação.

A aproximação com esses dados indica a demanda da accountability das políticas e ações da administração pública, especialmente quando nem mesmo os meios legítimos têm sido garantidos, como acontecia com o Fórum antes da intervenção do governo Temer.

Alguns municípios garantiram, no âmbito do plano municipal, os mecanismos de acompanhamento das metas. No caso de Ituiutaba/MG, o PDME define, como estratégia 1.19 (ITUIUTABA, 2015), a criação de um Conselho de Educação Infantil para acompanhar a execução das estratégias definidas, o que ainda está em processo de implementação, com a participação de representantes da Secretaria Municipal de Educação, professores dos estabelecimentos de ensino públicos de Educação Infantil e representantes sindicais, de pais e das instituições de ensino superior da região.

\section{Meta 1 do Plano Nacional de Educação: situação da Educação Infantil}

No Brasil, de acordo com os dados do Censo Escolar da Educação Básica (BRASIL, 2017 b), foram matriculadas 872.564 crianças em creches em período parcial no ano de 2017 , envolvendo as dependências administrativas estaduais e municipais, e 1.337 .218 em creches de período integral. Na pré-escola, a quantidade de matrículas em período parcial foi de 3.492.039, ao passo que no integral foram apenas 380.726. De forma geral, na rede pública, o número de crianças em creches corresponde a 2.209.782, e na pré-escola, 3.872.768. No caso do estado de Minas Gerais, 189.120 crianças foram matriculadas em creches, enquanto 365.424 estão na pré-escola.

Ituiutaba/MG possui densidade demográfica de $37,40 \mathrm{hab} . / \mathrm{km}^{2}$ e aproximadamente 104.526 pessoas residentes (BRASIL, 2017c), de acordo com a estimativa do Instituto Nacional de Geografia e Estatística (IBGE), publicada em $1^{\circ}$ de julho de 2017. Notam-se, ainda, demandas de uma cidade interiorana, com média salarial de 2.2 salários mínimos em 2015 (BRASIL, 2015).

Na Educação Infantil do referido município, não há oferta da rede estadual, visto que as vagas públicas estão na dependência administrativa municipal, decorrentes da 
municipalização dessa etapa da Educação Básica - 304 crianças estão em creches, considerando os regimes parcial e integral; e 1.420 nas pré-escolas, com um total de 1.724 matrículas na Educação Infantil da rede municipal (BRASIL, 2017b). Ao avaliar os dados referentes a dois anos antes da aprovação do PNE (BRASIL, 2014) até o contex to atual, observa-se uma elevação na quantidade de matrículas, mas em valores muito modestos, como indica o Gráfico 1: a pré-escola, que em 2012 registrava 1.285 alunos matriculados, em 2017 passou para 1.420. Se for considerado o ano de aprovação do PNE (2014) e 2017, o acréscimo foi de apenas $0,086 \%$.

Gráfico 01 Número de matrículas em pré-escola, dependência administrativa do município de Ituiutaba/MG

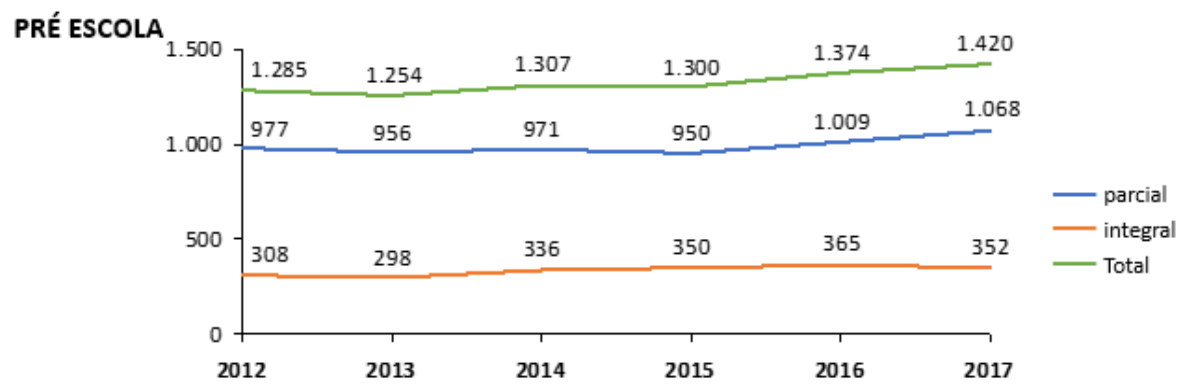

Fonte: Inep (BRASIL, 2017b.). Elaborado pelas autoras.

Nas creches municipais de Ituiutaba/MG, o número de matrículas teve aumento significativo: em 2012, foram 160, e em 2013, 206. Entre o ano de aprovação das metas do PNE (BRASIL, 2014), no qual foram matriculadas 251 crianças, e 2017, com 304 inscrições, houve avanço de aproximadamente $21 \%$, como pode ser verificado no Gráfico 2.

Gráfico 02 Número de matrículas em creche, dependência administrativa do Município de Ituiutaba/MG

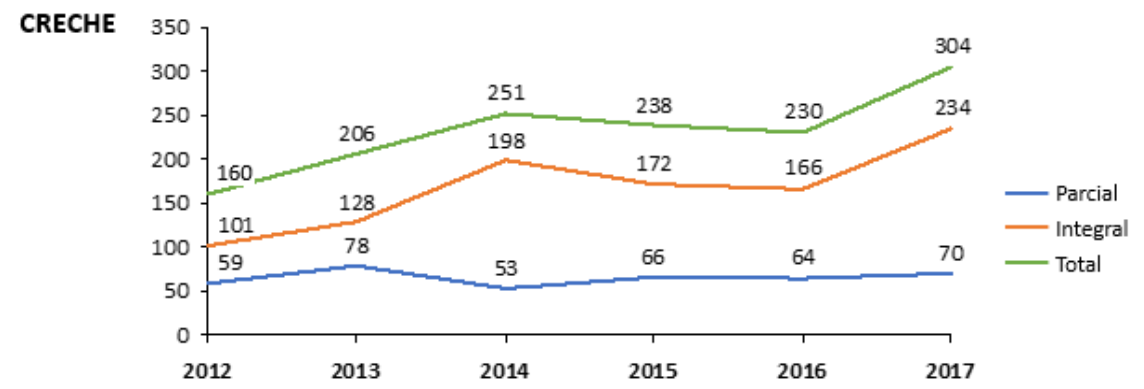

Fonte: Inep (BRASIL, 2017b.). Elaborado pelas autoras. 
Não obstante, a avaliação da meta 1 (PNE, 2014; PDME, 2015) demanda a relação do número de matrículas com o contingente populacional na faixa etária da educação infantil no município. Essa avaliação da efetivação das metas do PNE é acompanhada pelos dados oficiais, assumindo como referência a base de dados do último censo populacional realizado em 2010, de acordo com indicação do Simec.

Entretanto, o Estado dispõe do Sistema IBGE de Recuperação Automática (SIDRA) (BRASIL, 2017c) no qual está disponível a estimativa de população residente por idade. Assim, selecionamos a estimativa, no ano de 2017, de idade na faixa etária entre zero e cinco anos de idade, evidenciando-se os seguintes dados: 1.137 com menos de um ano; 1.223 com um ano de idade, 986 com dois anos; 1.325 com três anos; 1.213 com quatro anos; e 1.215 com cinco anos.

Ao considerar as estimativas dos dados populacionais e a quantidade de matrículas para creches e pré-escolas no município no ano de 2017, obtiveram-se os índices de $6.5 \%$ e de $58 \%$, respectivamente, para a creche e pré-escola, na efetivação da meta 1 na rede pública municipal, como destacado abaixo.

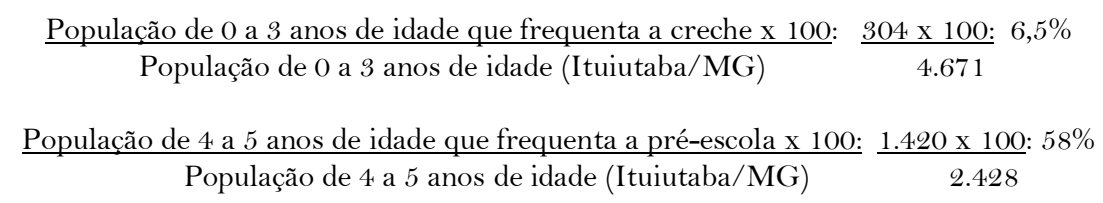

Assim, há de se questionar os dados oficiais quanto à real efetivação da ampliação dos números diante da meta 1, assim como, as condições das instituições de Educação Infantil por meio da quais se tem ampliado o índice de vagas, uma vez que dentre as alternativas assumidas estão as creches conveniadas e a indicação da compra de vagas na rede privada.

Quatro estabelecimentos de ensino estão em construção, com recursos do FNDE. De acordo com a avaliação das metas do PMDE (ITUIUTABA, 2015).

As medidas para monitoramento e avaliação do PDME, no período de 2015 a 2024, envolvem: Fórum de Educação do Município, a ser organizado pela Secretaria Municipal de Educação, Esporte e Lazer, em parceria com as demais entidades representativas da educação no município nas esferas municipal, estadual, federal e privada (SRE, IES, Sindicatos) - dois anos; audiências públicas a cada três anos (para socialização das realizações, avanços, estudos, novas demandas da sociedade); pesquisa periódica junto às escolas para acompanhamento das ações, resultados e evolução dos indicadores; atuação dos colegiados e conselhos escolares e municipais, existentes ou criados por ação do PDME, com relação aos objetivos do plano. (ITUIUTABA, 2015, P. 39) 
Tais dados geram provocações quanto ao atendimento ou não das vagas necessárias às pré-escolas e creches. Como as últimas não são obrigatórias, elas ainda são um direito da criança e das famílias, em que devem ter acesso ao serviço quando desejarem, haja vista ser uma garantia constitucional a esses sujeitos de direito. Como a creche é uma opção da família, nem sempre há, por parte dos municípios, a transparência quanto às pessoas que pretendem matricular seus filhos, mas não têm vagas garantidas na rede pública.

De acordo com as notas estatísticas elaboradas pelo Instituto Nacional de Estudos e Pesquisas Educacionais Anísio Teixeira (INEP) em 2017 (BRASIL, 2018b), as matrículas na Educação Infantil do país estão distribuídas em 67.902 instituições que funcionam como creches e 105.200, como pré-escolas, sendo que a mesma instituição pode ofertar mais de uma etapa de ensino; logo, é possível computar 116,5 mil estabelecimentos de Educação Infantil. Quando se avalia a evolução na quantidade dessas instituições entre 2013 e 2017, evidencia-se uma estagnação, pois houve apenas um acréscimo de 19,4\% no número de escolas que oferecem creche, além da redução na quantidade de pré-escolas - de 108.470 em 2013 para 105.200 em 2017.

Ao contrapor esses dados com a meta 1 do PNE (BRASIL, 2014), de universalizar a pré-escola sem a notória ampliação de instituições, questiona-se onde (e como) tem se ampliado o acesso, assim como as condições para isso. Nesse caso se destaca a seguinte realidade dos estabelecimentos escolares: segundo dados do Inep, em 2017 (BRASIL, 2018b), $61,1 \%$ das creches possuíam banheiro adequado à Educação Infantil, enquanto apenas 33,9\% tinham berçário. Essencial na organização da rotina e no trabalho com a criança pequena, o parque infantil está disponível em 57,6\% das creches e em 42,7\% nas pré-escolas (BRASIL, 2018b).

Segundo o Inep (BRASIL, 2018b), em 2017, 29,6\% das creches no país possuíam área verde, enquanto, nas pré-escolas, há 27,3\% com essa característica. Quanto à infraestrutura básica, como abastecimento de água, energia e saneamento, $8,5 \%$ das instituições de Educação Infantil não disponibilizam ao menos um desses recursos; 3,8\% não são abastecidas com água; 95,3\% dispõem de sistema público de energia; 97,6\% das creches e 94,6\% das préescolas possuem sistema de esgoto (rede pública ou fossa), e a cobertura é menor na zona rural, estando ausente em 9,4\% das creches e 12,6\% de pré-escolas. Essa realidade indica o desafio em garantir o desenvolvimento na Educação Infantil e os direitos das crianças e dos profissionais que trabalham em tais instituições. 
Sem a garantia de recursos da União diante do contingenciamento de investimentos para a educação, como discutido anteriormente, é quase contraditório que a LDB (9.394/96) demande que as instituições de Educação Infantil sejam submetidas aos mecanismos de credenciamento, reconhecimento e supervisão do sistema de ensino ao qual estão integradas (Art. $9^{\circ}$, inciso IX, art.10, inciso IV e art.11, inciso IV), ao passo que existem instituições públicas em funcionamento que não têm nem mesmo abastecimento de água, conforme dados do Inep de 2018.

Tal fato é lamentável quando todos os brasileiros têm direitos constitucionais em relação a essa etapa da Educação Básica, especialmente quando se assume uma concepção de Educação Infantil como imprescindível na construção dos sistemas de representação da criança - no campo humano/simbólico, isso está relacionado às diferentes formas de linguagens/comunicação da pessoa. Essa função da Educação Infantil envolve as dimensões afetiva, psicomotora, cognitiva e social, e, para tanto, requer uma concepção pedagógica sólida e condições materiais/econômicas, pedagógicas e profissionais para o pleno desenvolvimento (CAMPOS, 2013).

Como sustenta Saviani (2017, p. 660), o contexto brasileiro atual indica uma crise política que desafia a restabelecer a "democracia formal destruída pelo golpe jurídicomidiático parlamentar" - dentre os inúmeros impactos, há medidas arbitrárias diversas. Essa perspectiva afeta políticas e programas voltados à efetivação do acesso e da qualidade, como o Programa Nacional de Reestruturação e Aquisição de Equipamentos para a Rede Escolar Pública de Educação Infantil (PROINFÂNCIA), que pretende ampliar o acesso de crianças a creches e pré-escolas e melhorar a infraestrutura física dessas instituições. A Resolução n. 6, de 24 de abril de 2007 (BRASIL, 2007b), que regulamenta o Proinfância, indicava a intervenção da União em municípios sem condições de atender às demandas da Educação Infantil diante dos recursos limitados. Programas como esse que fornecem recursos para construção, reforma, equipamentos e mobiliários da rede pública são essenciais, em se tratando da realidade dos municípios e da demanda por novas unidades de Educação Infantil e/ou melhorias nas já existentes.

O corte orçamentário indica, ainda, a falta de políticas de Estado para a Educação Infantil, de forma a garantir o regime colaborativo entre a União e os entes federados nas demandas dessa etapa da educação. Não obstante, faz-se necessário acompanhar em todos os municípios se as dotações repassadas nos últimos anos envolvendo programas como o Proinfância impactaram quantitativa e qualitativamente nas creches e pré-escolas. 
A EC N. 95/2016 afronta diretamente a meta 20 do PNE (2014) e, consequentemente, a maioria das estratégias que necessitam de recursos, como as demandas da Educação Infantil. Essa medida pode provocar impactos na tentativa histórica de garantir uma pedagogia centrada no caráter lúdico da aprendizagem e na importância das interações entre crianças e adulto, criança e criança, criança e meio segundo os preceitos de imaginação, brinquedo, desafios do cotidiano e múltiplas expressões/linguagens (KISHIMOTO, 2001). Com a redução de recursos, não raro se tenta aproximar o trabalho da Educação Infantil às características do Ensino Fundamental, com a redução da educação e o cuidado às características de um ensino voltado para a aceleração da alfabetização. Diante dessas condições, o empobrecimento da concepção de educação e cuidado da criança na Educação Infantil pode aproximá-la de uma visão propedêutica, inclusive com a inserção de materiais apostilados ou terceirização da Educação Infantil.

De fato, a avaliação é essencial na accountability do Estado e dos entes federados para a efetiva implementação das políticas públicas de educação, sobretudo do PDME, o qual está em consonância com o PNE (Lei N. 13.005/2014), foco deste artigo.

\section{Em síntese}

Evidencia-se nas últimas décadas a atenção dada à Educação Infantil no Brasil. Todavia, o contexto político atual sinaliza novas e velhas necessidades, especialmente no sentido de atender às especificidades do cuidar e educar com intencionalidade pedagógica, sem afetar as características próprias da criança. Essa condição e característica da Educação Infantil requer amplo investimento por parte do Estado, seja para ampliar o número de matrículas em instituições apropriadas à faixa etária, provendo o respectivo acesso, seja para garantir materiais pedagógicos, condições de trabalho, formação de profissionais e outras exigências da organização da prática pedagógica com a criança de zero a cinco anos.

Conforme Luce e Farenzana (2007), a política como estratégia, metas e meios foi concebida centralmente. Porém, a execução é descentralizada, podendo ser distinguida tanto como descentralização convergente - uma vez que as ações do MEC e do ente que tenha firmado o compromisso se agregam em torno de diretrizes gerais previamente estabelecidas -, como descentralização monitorada, no que concerne às exigências de planejamento.

O Estado centraliza o planejamento, as orientações técnicas e o controle das políticas, e, paralelamente, descentraliza a responsabilidade pela implementação administrativa, 
embora assuma parceria financeira e apoio técnico (é sobre os entes federados que recai a responsabilidade em atingir as metas). Destarte, no campo educacional, poder-se-ia inferir que o Estado no Brasil está assentado em uma perspectiva que centraliza o controle e descentraliza a responsabilidade pela execução, nesse caso da educação infantil, recuando em conquistas históricas como as metas do atual PNE (2014), afetando, paralelamente os planos municipais de educação.

\section{Referências}

BRASIL. Constituição (1988). Constituição da República Federativa do Brasil. Brasília-DF: Senado Federal, 1988.

BRASIL. Lei no 8.069, de 13 de julho de 1990. Dispõe sobre o Estatuto da Criança e do Adolescente e dá outras providências. Diário Oficial da União, Brasília, DF, 27 de Nov. de 1990 .

BRASIL. Lei n. 9.394, de 20 de dezembro de 1996. Estabelece as Diretrizes e Bases da Educação Nacional. Diário Oficial da União, Brasília, DF, 23 de Dez. de 1996a.

BRASIL. Constituição (1988). Emenda Constitucional n. 14, de 12 de setembro de 1996. Modifica os arts. 34, 208, 211 e 212 da Constituição Federal e dá nova redação ao art. 60 do Ato das Disposições Constitucionais Transitórias. Diário Oficial da União, Brasília, DF, 12 de Set. 1996b.

BRASIL. Lei n. 9.424 de 24 de dezembro de 1996. Dispõe sobre o Fundo de Manutenção e Desenvolvimento do Ensino Fundamental e de Valorização do Magistério, na forma prevista no art. $60, \S 7^{\circ}$, do Ato das Disposições Constitucionais Transitórias, e dá outras providências. Diário Oficial da União, Brasília, DF, 24 de Dez. 1996c.

BRASIL. Ministério da Educação. Secretaria de Educação Fundamental. Referencial Curricular Nacional para a Educação Infantil. Brasília, DF: MEC/SEF, 1998.

BRASIL. Ministério da Educação. Secretaria da Educação Básica. Resolução nº 5/2009 da CNE/CEB, de 17 de dezembro de 2009. Diretrizes Curriculares Nacionais de Educação Infantil. Brasília: MEC/SEB, 2010.

BRASIL. Constituição (1988). Emenda Constitucional n.64, de 4 de fevereiro de 2010. Altera o art. $6^{\circ}$ da Constituição Federal, para introduzir a alimentação como direito social. Diário Oficial da União, Brasília, DF, 4 de Fev. 2010.

BRASIL. Constituição (1988). Emenda Constitucional n. 53 de 19 de dezembro de 2006. Dá nova redação aos arts. $7^{\circ}, 23,30,206,208,211$ e 212 da Constituição Federal e ao art. 60 do Ato das Disposições Constitucionais Transitórias. Diário Oficial da União, Brasília, DF, 12 de Set. 2006. 
BRASIL. Decreto n. 6.094, de 24 de abril de 2007. Dispõe sobre a implementação do Plano de Metas Compromisso Todos pela Educação, pela União Federal, em regime de colaboração com municípios, Distrito Federal e estados, e a participação das famílias e da comunidade, mediante programas e ações de assistência técnica e financeira, visando a mobilização social pela melhoria da qualidade da Educação Básica. Diário Oficial da União, Brasília, DF, 25 de Abr. de 2007a.

BRASIL. Resolução n. 6, de 24 de abril de 2007. Estabelece as orientações e diretrizes para execução e assistência financeira suplementar ao Programa Nacional de Reestruturação e Aquisição de Equipamentos para a Rede Escolar Pública de Educação Infantil - Proinfância. Diário Oficial da União, Brasília, DF, 2007b.

BRASIL. Constituição (1988). Emenda Constitucional n. 59, de 11 de novembro de 2009. [...] dá nova redação aos incisos I e VII do art. 208, de forma a prever a obrigatoriedade do ensino de quatro a dezessete anos e ampliar a abrangência dos programas suplementares para todas as etapas da Educação Básica, e dá nova redação ao $\$ 4^{\circ}$ do art. 211 e ao $\S 3^{\circ}$ do art. 212 e ao caput do art. 214, com a inserção neste dispositivo de inciso VI. Diário Oficial da União, Brasília-DF, 11 de nov. 2009a.

BRASIL. Portaria Ministério da Educação n. ${ }^{0} 1.407$ de 14 de dezembro de 2010. Institui o Fórum Nacional de Educação - FNE. Disponível em: http://fne.mec.gov.br/9uncategorised/926-portaria-1-407 Acesso em: 07 abr. 2018.

BRASIL. Lei n. 13.005, de 25 de junho de 2014. Aprova o Plano Nacional de Educação PNE e dá outras providências. Diário Oficial da União. Brasília: MEC, 2014.

BRASIL. Constituição (1988). Emenda Constitucional n. 95, de 2016. Altera o Ato das Disposições Constitucionais Transitórias, para instituir o Novo Regime Fiscal, e dá outras providências. Diário Oficial da União, Brasília, DF, 15 de dez. de 2016.

BRASIL. Ministério da Educação e Cultura. Portaria 577 de 27 de abril de 2017. Diário Oficial da União. Brasília: MEC, 2017a. Disponível em: http://www.abmes.org.br/arquivos/legislacoes/Port-MEC-577-2017-04-27.pdf. Acesso em: 02 abr. 2018.

BRASIL. Ministério da Educação. Instituto Nacional de Estudos e Pesquisas Educacionais Anísio Teixeira. Censo Escolar 2017, 2017b. Disponível em: www.inep.gov.br. Acesso em: 02 abr. 2018.

BRASIL. Sistema IBGE de Recuperação Automática - SIDRA. Diretoria de Pesquisas, Coordenação de População e Indicadores Sociais, Estimativas da população residente com data de referência $1^{\circ}$ de julho de 2017c. Disponível em: https://sidra.ibge.gov.br/tabela/6579. Acesso em: 02 abr. 2018.

BRASIL. LEI $\mathrm{N}^{\circ}$ 13.587, DE 2 DE JANEIRO DE 2018. Estima a receita e fixa a despesa da União para o exercício financeiro de 2018. Diário Oficial da União, Brasília-DF, 3 de Jan. de $2018 \mathrm{a}$.

BRASIL. Ministério da Educação. Instituto Nacional de Estudos e Pesquisas Educacionais Anísio Teixeira. Censo Escolar 2017- Notas Estatísticas. Brasília-DF 31 jan. de 2018b. 
CAMPOS, Maria Malta. Entre as Políticas de Qualidade e a Qualidade das Práticas. Cadernos de Pesquisa v.43 n.148 p.22-43 jan./abr. 2013.

COSTA, Áurea de Carvalho. O regime de colaboração entre União, estados e municípios no financiamento da educação no Brasil. RBPAE, v.26, n.1, p.105-12 1, jan./abr. 2010.

DOURADO, Luiz Fernandes (Org.). Plano Nacional de Educação (2011-2020). Goiânia: Editora da UFG; Autêntica, 2011.

FARIA, Ana Lucia. Educação pré-escolar e cultura. São Paulo: Cortez, 1999.

ITUIUTABA. Plano Decenal Municipal de Educação. Lei n. 4.368, de 17 de julho de 2015 Aprova o Plano Decenal Municipal de Educação - PDME de Ituiutaba-MG e dá outras providências. Prefeitura de Ituiutaba/MG, 2015.

KISHIMOTO, Tizuko Morchida. Brinquedos e materiais pedagógicos nas escolas infantis. Educação e Pesquisa, São Paulo, v.27, n.2, p. 229-245, jul./dez. 2001.

LUCE, Maria Beatriz; FARENZENA, Nalú. O regime de colaboração intergovernamental. In: GRACIANO, Mariângela (Coord.). Em questão: o Plano de Desenvolvimento da Educação (PDE). São Paulo: Ação Educativa, 2007, p.9-13. v.4.

EDITORIAL REVISTA EDUCAÇÃO \& SOCIEDADE. MEC e entidades da sociedade civil: o fórum nacional de educação. Educação E̊ Sociedade, v. 38, n. 139, p. 271-284, abr.-jun. 2017. Disponível em: http://www.scielo.br/pdf/es/v38n139/1678-4626-es-38-13900271.pdf. Acesso em: 21 de Jan. de 2018.

MINAS GERAIS. Plano Decenal De Educação Do Estado de Minas Gerais. Lei n. Lei no 19481, de 12 de janeiro de 2011. Institui o Plano Decenal de Educação do Estado de MG. Belo Horizonte/MG, $2011 . \quad$ Disponível em: https://www.almg.gov.br/consulte/legislacao/completa/completa.html?tipo=LEI\&num=1 9481\&ano=2011. Acesso em: 10 Jan. 2018

SAVIANI, Dermeval. Desafios da construção de um sistema nacional articulado de educação. Trab.educ. saúde. 2008, vol.6, n.2, p.213-232.

SAVIANI, Demerval. Democracia, educação e emancipação humana: desafios do atual momento brasileiro. Psicol. Esc. Educ. vol.21 no.3 Maringá, Sept./Dec. 2017. 